\title{
Open melody implant in a vascular graft-An alternative to the bioprosthetic valve?
}

\author{
Ming-Sing Si, MD
}

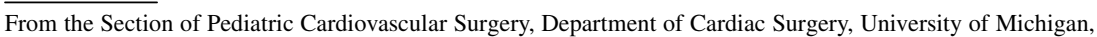
Ann Arbor, Mich.

Disclosures: Author has nothing to disclose with regard to commercial support.

Received for publication Sept 6, 2017; accepted for publication Sept 9, 2017; available ahead of print Oct 10, 2017.

Address for reprints: Ming-Sing Si, MD, 11-735 C.S. Mott Children's Hospital SPC 4204, 1540 E. Hospital Drive, Ann Arbor, MI 48109-4204 (E-mail: mingsing@umich.edu).

J Thorac Cardiovasc Surg 2018;155:742-3

$0022-5223 / \$ 36.00$

Copyright $(2) 2017$ by The American Association for Thoracic Surgery

https://doi.org/10.1016/j.jtcvs.2017.09.040

Transcatheter pulmonary valve replacement is a major technological breakthrough that has benefitted many pediatric and adult patients with congenital heart disease by the avoidance of open replacement, which requires the use of cardiopulmonary bypass. The Melody valve, the only transcatheter pulmonary valve approved by the Food and Drug Administration in 2010 for treating failing right ventricle to pulmonary conduits, has been implanted in more than 10,000 patients worldwide according to the website of the manufacturer, Medtronic (Minneapolis, Minn). The Melody valve can be implanted with a high success rate and has a favorable early and long-term risk profile. ${ }^{1}$ However, the Melody valve can't be seated and secured within a dilated right ventricular outflow tract (RVOT), seen in patients with tetralogy of Fallot who have received a transannular patch. Thus, patients with a dilated RVOT who meet the indications for pulmonary valve replacement undergo surgical placement of a bioprosthetic valve (BPV). The subsequent failure of the surgical BPV can then be treated with a Melody valve-in-valve placement, which is a useful technique that has been approved recently by the Food and Drug Administration as an official indication.

Deployment of the Melody valve in a BPV can be hampered by acute angulation of the BPV, inadequate landing zone, and severe calcification that is not amenable to dilation. To address these issues in patients undergoing surgical pulmonary valve replacement, Trezzi and colleagues ${ }^{2}$ present a novel technique to permit future implantation of a Melody valve. Their technique involves the open placement of a 24-mm Gore-Tex graft (W. L. Gore \& Associates, Inc, Flagstaff, Ariz) within the RVOT and main pulmonary artery, presenting of the graft, and placement of a Melody valve under direct vision within the presented graft. All procedures were performed with cardiopulmonary bypass. They have performed this technique in 8 patients with excellent outcomes at an average 26-month follow-up. One patient underwent redilation 2 months postoperatively for a $32 \mathrm{~mm} \mathrm{Hg}$ gradient.

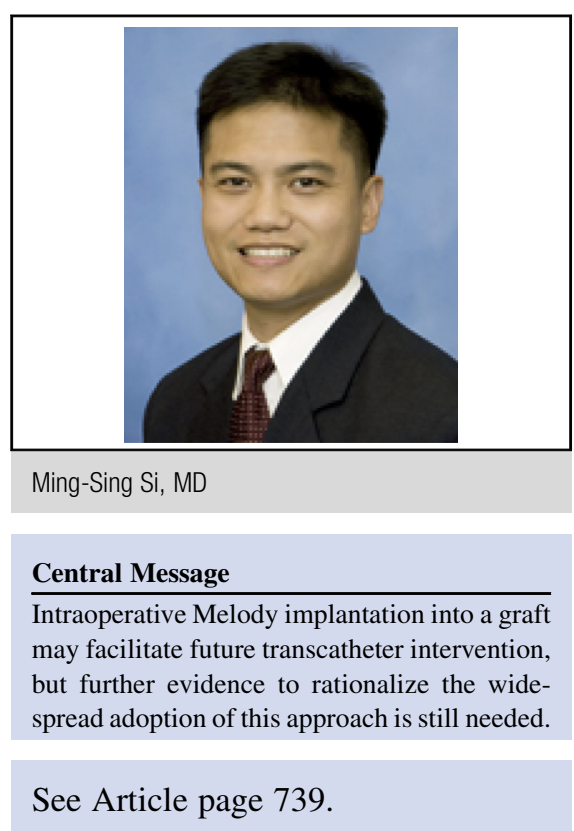

The technique proposed by Trezzi and colleagues ${ }^{2}$ certainly appears to address the potential issues that could be encountered with a future Melody in BPV approach in these patients with a dilated RVOT. However, the problems of BPV angulation, inadequate landing zone within the BPV, and severe BPV leaflet calcification appear to be infrequent. In a multicenter trial involving 8 US centers, 104 patients underwent Melody in BPV implantation. ${ }^{3}$ Implantation of the Melody valve was successful in all patients, who had 10 different types of BPVs. The authors of this study did illustrate a single case of BPV angulation relative to the RVOT, which was treated successfully with prestenting. In a recent study from a single center, 52 patients underwent Melody BPV implantation. ${ }^{4}$ In this study, only one procedure had to be aborted because of an inadequate landing zone, and there was no mention of the issue of BPV angulation in the RVOT.

Therefore, uniform adoption of this technique developed by Trezzi and colleagues ${ }^{2}$ for all patients requiring surgical pulmonary valve replacement may not be warranted. Rather, avoiding angulation during BPV implantation and earlier valve in valve intervention before the development of severe BPV calcification may be more practical. Studies are needed to determine which BPVs are the most favorable for subsequent Melody valve-in-valve intervention, and perhaps prosthetic valve 
manufacturers should take note and incorporate specific design elements into new BPVs that would facilitate future transcatheter intervention.

\section{References}

1. Chatterjee A, Bajaj NS, McMahon WS, Cribbs MG, White JS, Mukherjee A, et al. Transcatheter pulmonary valve implantation: a comprehensive systematic review and meta-analyses of observational studies. J Am Heart Assoc. 2017;6.
2. Trezzi M, Bandisode VM, Kavarana MN, Bradley SM. Surgical technique for placement of the Melody valve in a dilated right ventricular outflow tract. J Thorac Cardiovasc Surg. 2018;155:739-41.

3. Gillespie MJ, Rome JJ, Levi DS, Williams RJ, Rhodes JF, Cheatham JP, et al. Melody valve implant within failed bioprosthetic valves in the pulmonary position a multicenter experience. Circ-Cardiovasc Interv. 2012;5:862-70

4. Finch W, Levi DS, Salem M, Hageman A, Aboulhosn J. Transcatheter melody valve placement in large diameter bioprostheses and conduits: what is the optimal "Landing zone"? Catheter Cardiovasc Interv. 2015;86:E217-23. 